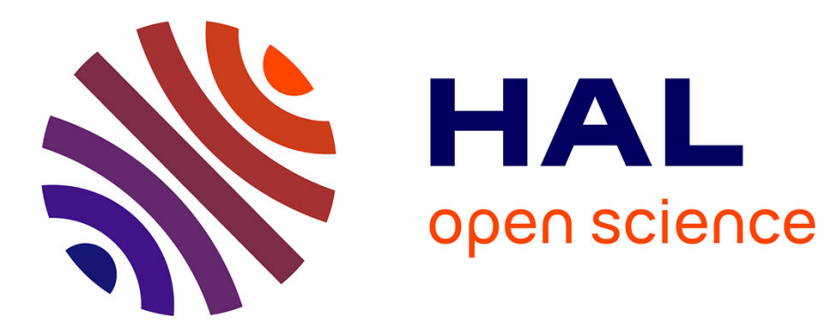

\title{
Wireless Sensors Networks Applications For Micro-Grids Management: State of Art
}

Mazen Takriti, Zina Boussaada, Ines Sansa, Octavian Curea, Najiba Mrabet Bellaaj

\section{- To cite this version:}

Mazen Takriti, Zina Boussaada, Ines Sansa, Octavian Curea, Najiba Mrabet Bellaaj. Wireless Sensors Networks Applications For Micro-Grids Management: State of Art. 2020 6th IEEE International Energy Conference (ENERGYCon), Sep 2020, Gammarth, Tunisia. pp.1058-1061, 10.1109/ENERGYCon48941.2020.9236519 . hal-03036439

\section{HAL Id: hal-03036439 \\ https://hal.science/hal-03036439}

Submitted on 2 Dec 2020

HAL is a multi-disciplinary open access archive for the deposit and dissemination of scientific research documents, whether they are published or not. The documents may come from teaching and research institutions in France or abroad, or from public or private research centers.
L'archive ouverte pluridisciplinaire HAL, est destinée au dépôt et à la diffusion de documents scientifiques de niveau recherche, publiés ou non, émanant des établissements d'enseignement et de recherche français ou étrangers, des laboratoires publics ou privés. 
archives-ouvertes

\section{Wireless Sensors Networks Applications For Micro-Grids Management: State of Art}

Mazen Takriti, Zina Boussaada, Ines Sansa, Octavian Curea, Najiba Mrabet Bellaaj

\section{To cite this version:}

Mazen Takriti, Zina Boussaada, Ines Sansa, Octavian Curea, Najiba Mrabet Bellaaj. Wireless Sensors Networks Applications For Micro-Grids Management: State of Art. 2020 6th IEEE International Energy Conference (ENERGYCon), Sep 2020, Gammarth, Tunisia. pp.1058-1061, 10.1109/ENERGYCon48941.2020.9236519 . hal-03036439

\section{HAL Id: hal-03036439 \\ https://hal.archives-ouvertes.fr/hal-03036439}

Submitted on 2 Dec 2020

HAL is a multi-disciplinary open access archive for the deposit and dissemination of scientific research documents, whether they are published or not. The documents may come from teaching and research institutions in France or abroad, or from public or private research centers.
L'archive ouverte pluridisciplinaire HAL, est destinée au dépôt et à la diffusion de documents scientifiques de niveau recherche, publiés ou non, émanant des établissements d'enseignement et de recherche français ou étrangers, des laboratoires publics ou privés. 


\section{Wireless Sensors Networks Applications For Micro- Grids Management: State of Art}

\author{
Mazen Takriti \\ Université de Tunis El Manar \\ Ecole Nationale d'Ingénieurs de Tunis \\ LR11ES15, \\ Laboratoire des Systèmes Electriques \\ 1002 Tunis, Tunisia \\ mazentakriti@hotmail.com
}

\author{
Octavian Curea \\ Univ. Bordeaux \\ ESTIA INSTITUTE OF \\ TECHNOLOGY \\ F-64210 Bidart, France \\ o.curea@estia.fi
}

\author{
Zina Boussaada \\ Univ. Bordeaux \\ ESTIA INSTITUTE OF \\ TECHNOLOGY \\ F-64210 Bidart, France \\ z.boussaada@estia.fr
}

\author{
Najiba Mrabet Bellaaj \\ Université de Tunis El Manar \\ ${ }^{1}$ Institut Supérieur d'Informatique \\ ${ }^{2}$ Ecole Nationale d'Ingénieurs de Tunis \\ LR11ES15, \\ Laboratoire des Systèmes Electriques \\ 1002 Tunis, Tunisia \\ najiba.bellaaj@isi.utm.tn
}

\author{
Ines Sansa \\ Université de Tunis El Manar \\ Ecole Nationale d'Ingénieurs de Tunis \\ LR11ES15, \\ Laboratoire des Systèmes Electriques \\ 1002 Tunis, Tunisia \\ sansa.ines@yahoo.com
}

\begin{abstract}
The complexity and the decentralization of MicroGrids have led to management and diagnosis issues because of using distributed power sources, especially the renewable energy sources. Wireless Sensor Networks can substitute part of the communication infrastructure of the Micro-Grid, it deploys between its elements in order to ensure data flow in real time. It allows energy management applications to have more interesting cost and efficiency. The present work discusses the Wireless Sensor Networks usage dedicated to energy management and default diagnosis in Micro-Grids.
\end{abstract}

Keywords-Micro-Grid, Sensor Network, Energy Management, Default Diagnosis.

\section{INTRODUCTION}

The present power grid is going through an enormous transformation which has emerged a new approach: the Micro-Grid (MG) [1]. It comprises Distributed Sources (DS), storage devices and loads [2], and it became the fundamental subcomponent of the power grid. The MG interest rises because of its structure, the perspective of a scalable and viable approach to integrate DS which increases the apportionment over a wide area [3]. Between different types of DSs, renewable energy sources become more widespread in MG because of environmental factors and the unavailability of fossil fuels [2]. Thus, MG deployment leads to an enormous increasing and complex structure which need a particular interest for the energy management issues.

In general, there are two management types for electric grids: centralized and decentralized. In a decentralized management, the control system is based on a network of autonomous local controllers, each responsible for an entities which are controlled in harmony with the system goals [4]. This increases the communication speed and fault tolerance, the wrong decisions of the devices may affect locally, but not as a whole grid when an operator is responsible to run the entire system, it is the case of centralized control [5]. Because of the distributed character of $\mathrm{MG}$, traditional management systems, which are designed to manage large production units operating under a centralized way, can hardly manage a MG.
Thus, the management mechanism of MG must be done in a decentralized way [3].

In previous works we discussed the efficiency of several techniques use in MG energy management. We took into account the decentralized way of the MG operation and the different management objectives [3]. From a perspective view of management, the primary intention of $\mathrm{MG}$ is to ensure energy delivery to loads, reducing operational cost and environmental emissions while stabilizing the electrical infrastructure [3,6]. The Multi Agents Systems (MAS) technique is very useful to manage and control MG elements and operation because of its decentralized working even when the MG is connected to the main grid or islanded [7]. These intelligent algorithms need the availability of information to be collected in real time. To do this, MG is richly interwoven with several sensors connected through a Wireless Sensor Network (WSN) [8].

WSN becomes an important part of MGs as its use is considered as cost effective solution for many purposes: to control, to monitor, to measure in MG [1]. WSN is widely used in several fields: military [9], agriculture [10], medicine [11], industry [12] and in electric energy applications [13].

In this paper, we will discuss the uses of WSNs for the management and he default diagnosis of MGs. The paper is organized as follows: in Sections II, we started with the definition of the MG, its structure and its operation modes. In section III we introduce the basic concepts of WSNs. Thereafter, a review of their uses in MG, in the interest of both issues, respectively, management and control, and default diagnosis. Finally, we concluded the paper in Section IV.

\section{MICRO-GRID}

\section{A. Micro-Grid Definition}

The MG is a power grid subcomponent which delivers electrical energy to a small community. According to the U.S. Department of Energy (DOE), MG is defined as "a group of interconnected loads and distributed energy resources within clearly defined electrical boundaries that acts as a single controllable entity with respect to the grid" [14]. 


\section{B. Micro-Grid Structure}

MG structure is not always the same, whether it operates in Direct Current (DC) or Alternating Current (AC) depending on the utilities, each MG includes an electrical infrastructure superimposed with a communication one.

The electrical infrastructure ensures the power flow in the MG and consists typically of three types of components: Distributed Sources (DS), distributed storage devices, and different loads [2]. DSs are the generators of electric energy in the MG. They can work with fossil fuels (diesel, gas turbine, etc.) or with renewable resources (photovoltaic, wind turbine, etc.). Distributed storage devices (flywheels, energy capacitors, batteries, etc.) ensure the energy storage in order to provide it to loads if necessary [2]. Loads are the consumption devices of the MG which can be linear or nonlinear.

The communication infrastructure of the MG is the WSN deployed on the system in order to ensure the data flow. It gathers different measurement as for example consumption, weather conditions, power production, etc. These measurements are very important for the control of the MG [15].

An example of residential MG that can be connected to the main grid is illustrated in Fig. 1.

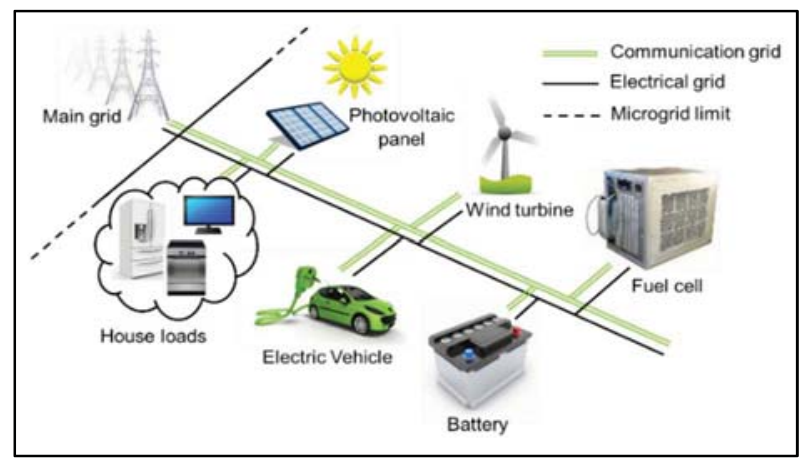

Fig. 1. An example of Micro-Grid structure

\section{Micro-Grid Operation Modes}

MGs are localized grids that can disconnect from the main grid to operate autonomously. There are two operation modes for $\mathrm{MG}$ :

- Grid-connected mode: where MG exchanges electric energy with the upper level grid which is called the main grid.

- Islanded mode: electrically isolated, MG has no energy exchange with main grid [7].

\section{WIRELESS SENSOR NETWORKS FOR MICRO-GRIDS}

MG operation needs to be equipped with tools able to communicate with $\mathrm{MG}$ elements and environment in order to collect information about the energy consumption behavior, energy production, environment condition and the storage,. The collected data facilitate the enhance of the reliability of the MG and the management of energy balance by means of different algorithms applied to the demand response balancing [16]. The data collect about the different elements of the MG can be accomplished using sensing, metering, and communication services [17].

In MGs, sensors are used for detecting faults, component failures, malfunctions, and sensing environmental conditions.
WSN is a group of sensors that could communicate with wireless technology having low operational and implementation costs [18].

In fact, sensors are battery-powered devices with limited resources. For that, characteristics as storage capacity, processing speed, and communication bandwidth need to be taken into account when developing WSN; particularly, in the context of $\mathrm{MG}$, where extensive communication among sensors is needed [15].

\section{A. Challenges of Wireless Sensor Network in Micro-Grids}

Most electric MG infrastructure has only the minimum level of monitoring and automation and the majority of critical equipment of the MG is not even monitored, because the existing remote sensing, monitoring, and fault diagnostic solutions are still expensive to be applied on a large-scale and pervasive basis [13]. In order to cognize the equipment condition which enables $\mathrm{MG}$ to respond to the changing conditions in an appropriate manner and proactive way. The WSN submitted the cost and energy effective solution to do that [19].

WSN can be used for DS that located in harsh environments to control the MG energetic behavior and monitor intermittent energy production [1]. Their unpredictable behavior breeds more challenges in the $\mathrm{MG}$ management and operation. Various parameters of DS and loads can be effectively measured and communicated using WSN, in order to control the energy balance in MG.

The great interest in WSN technologies due to having a number of advantages as interesting cost, energy economic, easy deployment and flexibility [13]. Otherwise, there is several challenges of implementing WSNs in MG communication:

- Environment- in MG environments, the sensors may be subjected to Radio Frequency (RF) interference, corrosive or caustic environment, dirt, dust, and other conditions that affect their performances [20].

- Security- this plays a definitive part in the design of WSN to prevent attacks and interventions. These include external attacks, eavesdropping, or jamming attacks and other active attack techniques (node capturing, routing attacks, flooding) [1].

- Remote access- integration with the internet and other sensor networks became necessary to access data or control of WSN, that complex the architecture as there is a protocol translation needed for all data packets.

- Reliability and latency requirements- The control and management of an islanded mode of MG is a timesensitive operation. It becomes a difficult issue to achieve quality-of-service requirements and other network specifications such as latency, packet loss, congestion control etc. [19].

- Deployment and autonomy- WSNs will have a large number of nodes spread over MGs. In most instances, the placement of these nodes can be random, this requires the WSN nodes to establish connections and maintain network connectivity autonomously.

\section{B. Wireless Sensor for Micro-Grid Management}

The literatures is rich with examples of WSNs implementation in MGs for the management and control. 
Indeed, WSN in MG for management purposes and control has been presented in [17], [21], [22], and surveyed in [23].

The study in [17] focused on residential energy management in order to reduce cost by managing the loads through optimization scheme uses, whereby proposing an energy management tool based on IEEE 802.15.4 protocol. The tool performance under various scenarios was evaluated such as priority-based scheduling. By simulation, a ZigBee sensor network has been used to control loads, Apart from providing an optimizing scheme, this simulation study does an initial analysis of sensor network parameters such as delay, delivery ratio, and jitter, in consideration of monitoring application with fixed and varying packet sizes. Network topology is presented in Fig. 2 where ZigBee allows two types of devices: Full Function Device (FFD) which can communicate with their peers and Reduced Function Device (RFD) which are simpler as edge nodes. As a result, WSN performances decreased with increasing packet size and the jitter was negligible.

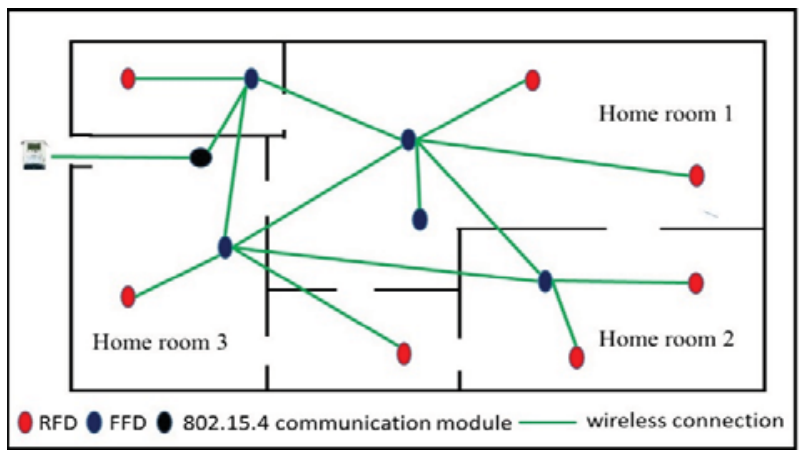

Fig. 2. Wireless Sensor Home Area Network topology [17]

In [15], the authors investigated the same communication protocol used in [17] by comparing two routing topologies in the context of MG (Fig. 3), in order to make energy and cost more effective. Simulation results showed that the reliability, service quality, packet loss, delay, and energy consumption issues, can be achieved by used topology. Mention that, in order to keep the WSN in longer duration energy constraints parameters for the sensors as the listening of the channel, routing protocol frames exchange, retransmission when error and the number of nodes to reach the coordinator, should be degraded by the network.

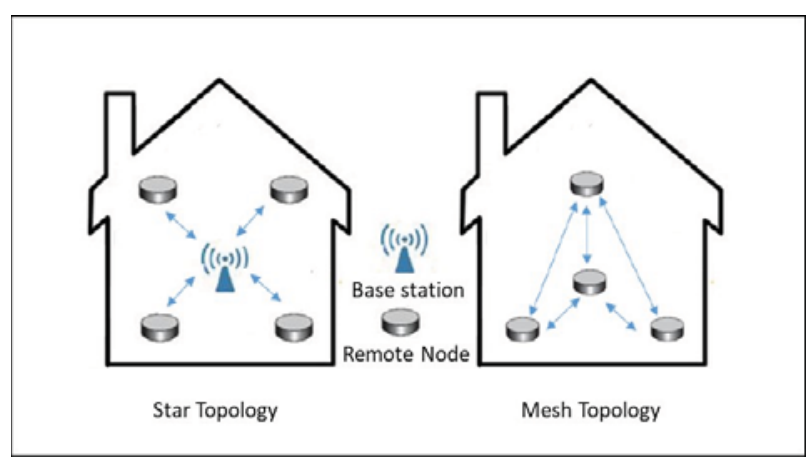

Fig. 3. Wireless Sensor Network different topology [15]

Another type of communication has been used in [24], where low power, wide area network (LoRaWAN) proposed to achieve a higher coverage range in $\mathrm{MG}$, allowed the integration of sensors that can be located far away from the
MG core. By implementation, LowRaWAN node should obtain online voltage and current reading of several $\mathrm{MG}$ sources by using modules and energy meter. In order to monitor and optimize the management of $\mathrm{MG}$, which can be done by obtaining information from heterogeneous data sources, and evaluated both packet loss and quality of signals. WSN has been implemented to increase the capabilities of the existing monitoring system that allowed remote management for the MG.

\section{Wireless Sensor for Micro-Grid default diagnosis}

MG breakdown may be caused by element faults (PV disconnect or DS failure, battery problems, etc.), environmental factors (solar radiation, wind speed, etc.), or incorrect operation (DS dismiss, unbalance demand side management, etc.).

In [25] authors proposed decentralized voltage quality monitoring architecture based on employment of selforganized Sensor Networks. Each node could detect local voltage quality anomalies automatically, through this paradigm, each node can get access to performances of the monitored site (acquired by local data) and global performances of the MG (computed by data exchanges among neighbor nodes). Thus, it makes inclusive monitoring architecture highly scalable, self-organizing and distributed.

A fault diagnosis meter was developed in [26] based on a ZigBee WSN for photovoltaic DS in order to reduce the hardware size and conduct remote fault diagnosis. The proposed approach required extracting the energy data, realtime solar radiation and module temperature. It has the advantages of less learning time, higher accuracy, and less memory consumption. The fault diagnosis method discussed is to obtain current radiation and module temperature, both together used with the characteristics captured for the DS, which including the maximum output power, the voltage and current at that point and open-circuit voltage for the module array during the operation, then identify whether it is under normal operation or a fault has occurred. By experiment, results showed that mobile fault diagnosis meter based on intelligent method has a high level of accuracy in fault identification.

An experimental study [13] has presented a WSN implemented in different environments including industrial power control room, and underground network transformer vault. The study uses a communication tool that supports IEEE 802.15.4, and focused on how to characterize and measure link quality in WSN deployed in MG environment by using two different radio-hardware link-quality metrics one for energy signal, the other for chip error rate. It was concluded that the background noise changes with temperature and interference levels.

Experiments in [27], for Packet delivery measurement in intensive WSN deployment in three realistic environments, by using linear topology with a single sender for about 60 sensor nodes showed that the packet loss in the physical layer was about $10-30 \%$ and $50-80 \%$ communication energy is wasted in overcoming packet collisions. The study found that packet delivery performance is a function of sensor characteristics, environment, and physical layer coding scheme. 


\section{CONCLUSION}

WSNs consist of hundreds of sensor nodes that may be deployed in a relatively complex environment such as in the MG one. They are considered as a cost-effective solution for MG data collecting, and they are being used for several purposes. In this paper, we discussed the uses of WSNs for the management and the default diagnosis of MGs.

\section{ACKNOWLEDGMENT}

This work was supported by the Tunisian Ministry of Higher Education and Scientific Research under Grant LSEENIT-LR 11ES15 in QehnA group, and also supported by ESTIA-Research Laboratory in ESTIA institute of technology.

\section{REFERENCES}

[1] L. Chhaya, P. Sharma, G. Bhagwatikar, and A. Kumar, "Wireless sensor network based smart grid communications: cyber attacks, intrusion detection system and topology control," Electronics 6, no. 1: 5, March 2017.

[2] N. Hatziargyriou, ed. Microgrids: architectures and control, John Wiley \& Sons, 2014.

[3] Z. Boussaada, O. Curea, H. Camblong, N. Bellaaj Mrabet, and A. Hacala, "Multi-agent systems for the dependability and safety of microgrids," International Journal on Interactive Design and Manufacturing (IJIDeM) 10, no. 1, pp. 1-13, November 2014.

[4] C.S. Karavas, G. Kyriakarakos, K.G. Arvanitis, and G. Papadakis, "A multi-agent decentralized energy management system based on distributed intelligence for the design and control of autonomous polygeneration microgrids," Energy Conversion and Management 103, pp.166-179, 2015

[5] A. Goranović, M. Meisel, L. Fotiadis, S. Wilker, Albert Treytl, and Thilo Sauter, "Blockchain applications in microgrids an overview of current projects and concepts," IEEE 43rd Annual Conference of the IEEE Industrial Electronics Society (IECON), pp. 6153-6158, 2017.

[6] C. M. Colson, M. H. Nehrir, and R. W. Gunderson, "Distributed multiagent microgrids: a decentralized approach to resilient power system self-healing," IEEE 4th International Symposium on Resilient Control Systems, pp. 83-88, 2011

[7] Z. Boussaada, A. Remaci, O. Curea, O. Driss, H. Camblong, and N. M. Bellaaj, "Management Approach for Microgrid Operation Using Multi Agent System (MAS) Technique," 2017.

[8] J. Gubbi, R. Buyya, S. Marusic, and M. Palaniswami, "Internet of Things (IoT): A vision, architectural elements, and future directions," Future generation computer systems 29, no. 7, pp. 1645 1660, September 2013

[9] K. B. Jangam, S. K. R. SV, C. Sunkara, M. B. Talluri, Z. H. Shaik, and I. Shaik, "Wireless Sensor Network Design for Tactical Military Applications," International Journal of Applied Sciences, Engineering and Management 5, no. 2, pp. 05-08, 2016.

[10] L. Ruiz-Garcia, L. Lunadei, P. Barreiro, and I. Robla, "A review of wireless sensor technologies and applications in agriculture and food industry: state of the art and current trends," sensors 9, no. 6, pp. 47284750, 2009.

[11] D. Zhang, X. Wang, and X. Song, "New medical image fusion approach with coding based on SCD in wireless sensor network," Journal of Electrical Engineering \& Technology 10, no. 6 pp. 2384-2392, 2015.

[12] R. Nukala, K. Panduru, A. Shields, D. Riordan, P. Doody, and J. Walsh, "Internet of Things: A review from 'Farm to Fork'," IEEE 27th Irish Signals and Systems Conference (ISSC), pp. 1-6, 2016.

[13] V. Gungor, B. Lu, and G. Hancke, "Opportunities and challenges of wireless sensor networks in smart grid," IEEE Industrial Electronics, Transactions on, vol. 57, no. 10, pp. 3557-3564, October 2010.

[14] Ton, Dan T., and Merrill A. Smith, "The US department of energy's microgrid initiative," The Electricity Journal 25, no. 8 pp. 84-94, 2012.

[15] A. Elmouatamid, N. Elkamoun, F. Lakrami, and M. Bakhouya, "Wireless sensor networks for smart micro-grids," Proceedings of the Congrès Méditerranéen des telecommunications (CMT’2018), El Jadida, Morocco, 2018.

[16] A. Llaria, Alvaro, G. Terrasson, O. Curea, and J. Jiménez, "Application of wireless sensor and actuator networks to achieve intelligent microgrids: a promising approach towards a global smart grid deployment," Applied Sciences 6, no. 3, p. 61, 2016.

[17] M. Erol-Kantarci \& H. Mouftah, "Wireless Sensor Networks for CostEfficient Residential Energy Management in the Smart Grid," IEEE Transactions on Smart Grid, Vol. 2, Issue: 2, pp. 314 - 325, March 2011.

[18] F. H. Aghdam, and N. T. Kalantari, "Energy Management Requirements for Microgrids," Springer In Microgrid Architectures, Control and Protection Methods, pp. 233-253, Cham, 2020.

[19] P. Sharma, and G. Pandove, "A Review Article on Wireless Sensor Network in Smart Grid," International Journal of Advanced research in computer science 8, no. 5, May 2017.

[20] V. C. Gungor and G. P. Hancke, "Industrial wireless sensor networks: Challenges, design principles, and technical approaches," Industrial Electronics, IEEE Transactions on, vol. 56, no. 10, pp. 4258-4265, 2009.

[21] B. Lu and V. C. Gungor, "Online and remote motor energy monitoring and fault diagnostics using wireless sensor networks," IEEE Trans. Ind. Electron., vol. 56, no. 11, pp. 4651-4659, November 2009.

[22] R. Leon, V. Vittal, and G. Manimaran, “Application of sensor network for secure electric energy infrastructure," Power Delivery, IEEE Transactions on, vol. 22, no. 2, pp. 1021-1028, April 2007.

[23] Y. Yang, F. Lambert, and D. Divan, "A survey on technologies for implementing sensor networks for power delivery crosssystems," IEEE Power Engineering Society General Meeting, pp. 1-8, June 2007

[24] E. López, J. Monteiro, P. Carrasco, J. Sáenz, N. Pinto, and G. Blázquez, "Development, implementation and evaluation of a wireless sensor network and a web-based platform for the monitoring and management of a microgrid with renewable energy sources," IEEE International Conference on Smart Energy Systems and Technologies (SEST), pp. 1-6, 2019.

[25] M. Di Bisceglie, C. Galdi, A. Vaccaro, and D. Villacci, "Cooperative sensor networks for voltage quality monitoring in smart grids," IEEE In Bucharest PowerTech, pp. 1-6, 2009.

[26] K. H. Chao, P. Y. Chen, M.H. Wang, and C. T. Chen, "An intelligent fault detection method of a photovoltaic module array using wireless sensor networks," International Journal of Distributed Sensor Networks 10, no. 5, 2014.

[27] J. Zhao, and R. Govindan, "Understanding packet delivery performance in dense wireless sensor networks," In Proceedings of the 1 st international conference on Embedded networked sensor systems, pp. 1-13, 2003. 